\section{Health-promoting Carotenoids and Phenolics in 31 Capsicum Accessions}

\author{
Ivette Guzman, Krystal Vargas, Francisco Chacon, Calen McKenzie, \\ and Paul W. Bosland \\ Department of Plant and Environmental Sciences, New Mexico State \\ University, Las Cruces, NM 88003
}

Additional index words. carotenoid, chile pepper, lutein, macular pigment, phenolics

\begin{abstract}
This study investigated the diversity of carotenoids and phenolics in germplasm from three Capsicum (chile pepper) species, Capsicum annuum, Capsicum baccatum, and Capsicum chinense. Lutein, a yellow-pigmented carotenoid, and phenolics, a group of secondary metabolites, are reported to have health-promoting properties. The germplasm studied matured to a yellow color. The hypothesis was that all yellow fruits would contain either the carotenoid lutein, a yellow pigment, or a large amount of phenolics, a group of secondary metabolites that may be yellow among other colors. Thirty-one Capsicum accessions were grown in the field over a period of two seasons. On a dry weight (DW) basis, lutein ranged from 0.14 to $94.2 \mu \mathrm{g} \cdot \mathrm{g}^{-1}$, and total phenolics ranged from 5.79 to $15.01 \mathrm{mg} \cdot \mathrm{g}^{-1}$. No lutein was detected in one accession and $\beta$-carotene, another healthpromoting compound, was lacking in four accessions. Accessions were grouped into four groups according to a principal component analysis plot. Results from this study indicate that in only nine accessions, lutein represented at least $50 \%$ of the total carotenoid amounts in each accession. These accessions are desirable not only as a source of dietary lutein, a natural yellow pigment, but also as genetic material that can be used to breed for higher lutein Capsicum. Therefore, yellow color is not a good indicator of lutein content and phytochemical analysis is required to determine the content of health-promoting compounds.
\end{abstract}

In Capsicum, 39 species have been identified including five domesticated species, $C$. annuum, C. baccatum, C. chinense, Capsicum frutescens, and Capsicum pubescens (Carrizo García et al., 2016). Chile peppers are an important culinary spice. Historically, the cultural value of chile peppers includes medicinal and culinary uses (Cichewicz and Thorpe, 1996; Guzman et al., 2011); however, due to the rich color palette of the fruits, they are potential sources of natural colorants with dietary health-promoting properties and thus have been gaining more attention as a source of pigments for foods and textiles due to their biological activity (Arimboor et al., 2015; Ksibi et al., 2015).

As chile pepper fruits mature, they become yellow, orange, red, or brown (Guzman

Received for publication 26 Mar. 2020. Accepted for publication 16 Oct. 2020.

Published online 20 November 2020

We thank Geno Picchioni and Stephanie Walker from New Mexico State University for reviewing this manuscript. We also thank Danise Coon and the Chile Pepper Institute staff for their technical assistance. Graduate and undergraduate student salaries and research were supported by the state and federal Hatch funds appropriated to New Mexico Agricultural Experiment Station and New Mexico State University's Maximizing Access to Research Careers program funded by the National Institutes of Health.

I.G. is the corresponding author. E-mail: ivguzman@ nmsu.edu.

This is an open access article distributed under the CC BY-NC-ND license (https://creativecommons. org/licenses/by-nc-nd/4.0/). et al., 2011; Kim et al., 2016a). One of the high-value qualities that Capsicum is bred for is color which is an accumulation of pigments determined by genetics and the environment (Guzman et al., 2010; Kim et al., 2016a; Stommel and Griesbach, 2008). Fruit pigmentation involves several groups of compounds including lipid-soluble carotenoids and water-soluble phenolics (Guzman et al., 2011; Rodriguez-Amaya, 2019).

The importance of natural pigments is highlighted by the possible negative linkage between synthetic pigments and human behavior issues (Kanarek, 2011; McCann et al., 2007). Capsicum fruits produce a red-colored oleoresin that is a good source of red pigments used in (Arimboor et al., 2015); however, yellow Capsicum pigments are also valuable pigments in that they play important roles in human health (Bernstein et al., 2016). Capsicum may contain up to $10.76 \mathrm{mg} \cdot \mathrm{g}^{-1} \mathrm{DW}$ of total carotenoids (Guzman et al., 2010; Kim et al., 2016a). Carotenoids are shades of yellow, orange, and red, and include nutritionally important compounds like $\beta$-carotene, which is a vitamin $\mathrm{A}$ source. Lutein is among the few plant phytocompounds that can be absorbed by the human digestive tract, as well as passed on from a nursing mother's breast milk to her infant (Lipkie et al., 2015). Once lutein enters the human blood stream, it reaches the retina, where it becomes the macular pigment, protecting the eyes from oxidative blue light and reducing cataract formation (Bernstein et al., 2016).

In addition to carotenoids, Capsicum fruits contain phenolic compounds that also human food, animal food, and cosmetics contribute to color and health-promoting antioxidant properties (Materska and Perucka, 2005; Taofiq et al., 2017). Plant phenolic compounds are a group of water-soluble metabolites that help plants adapt to abiotic and biotic stresses (Taofiq et al., 2017). Included in the diverse phenolic group are multiple categories of plant compounds consisting of simple and complex phenolic compounds (phenolic acids, coumarins, flavonoids, stilbenes, and tannins) (Minatel et al., 2017; Waterhouse, 2002). Due to their unique structures, they serve as strong antioxidants, and have been shown to have antidiabetic properties (Kim et al., 2016b). Their healthpromoting and chronic disease prevention properties make them ideal for nutraceutical and functional foods (Brown et al., 2014; Guzman et al., 2015; Yousef et al., 2014a, 2014b, 2016). Total phenolics for Capsicum range from 0.2 to $11.03 \mathrm{mg} \cdot \mathrm{g}^{-1}$ gallic acid equivalents in dry tissue (Carvalho et al., 2015; de Aguiar et al., 2016; Joshi et al., 2017). Major phenolics found in Capsicum fruits were identified as derivatives of quercetin, ferulic acid, sinapic acid, apigenin, and luteolin (Materska and Perucka, 2005).

Due to genetic variability, there is a considerable difference in carotenoid and phenolic amounts across chile pepper cultivars (Carvalho et al., 2015; Guzman et al., 2010; Joshi et al., 2017; Materska and Perucka, 2005). In a previous study, the $\beta$-carotene concentrations in orange pepper fruits ranged from 0 to $1.24 \mathrm{mg} \cdot \mathrm{g}^{-1} \mathrm{DW}$ according to genotype (Guzman et al., 2010). The important implication of that research is that not all orange fruits contain $\beta$-carotene, a precursor to vitamin A. Consequently, the need exists for more chemical analysis profiling colored chile peppers with the potential to have high amounts of health-promoting nutraceuticals like lutein and phenolics. The hypothesis of this research was that health-promoting carotenoids and phenolic compounds are in equal amounts in yellow C. annuum, $C$. baccatum, and $C$. chinense fruits. The goal was to identify Capsicum genotypes that can be used by food scientists or by breeders attempting to increase nutritional value in Capsicum germplasm.

\section{Materials and Methods}

Plant material. Thirty-one Capsicum accessions from $C$. annuum, $C$. baccatum, and $C$. chinense with yellow maturing fruit, and one yellow Solanum melongena (eggplant) (Table 1) were sown in a planting medium (Sunshine Redi-Earth Plug \& Seedling Mix; Sun Gro Horticulture, Bellevue, WA) at the New Mexico State University (NMSU) Chile Pepper Institute greenhouse maintained at $27{ }^{\circ} \mathrm{C}$ day $/ 18{ }^{\circ} \mathrm{C}$ night $\pm 3{ }^{\circ} \mathrm{C}$ (Las Cruces, $\mathrm{NM}$ ) using previously published conditions (Bosland and Walker, 2014). Accessions were selected if their fruit color phenotype was yellow, although color intensity, hue, and chroma were not measured. After 8 weeks, seedlings were transplanted in Glendale loam soil at the NMSU Leyendecker 
Table 1. List of 31 Capsicum accessions with carotenoid and total phenolic (as gallic acid equivalents) means from 2 years, fruits from five plants each year, in $\mu \mathrm{g} \cdot \mathrm{g}^{-1}$ dry weight $(\mathrm{DW})$ and $\mathrm{mg} \cdot \mathrm{g}^{-1}(\mathrm{DW}) \pm \mathrm{sD}$.

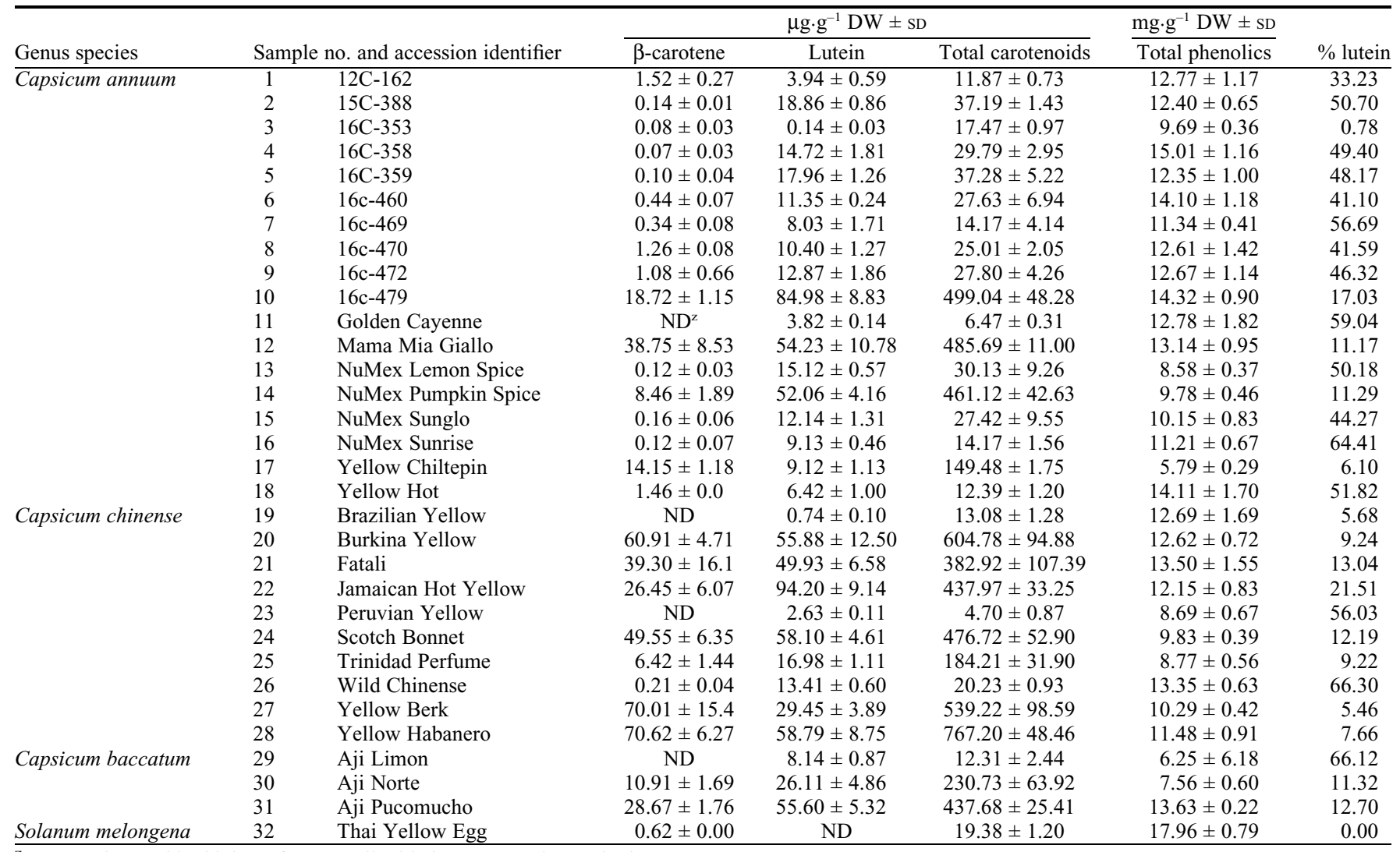

${ }^{\mathrm{z}} \mathrm{ND}$, not detected by high-performance liquid chromatography method.

Plant Science Center and Fabian Garcia Science Center in Las Cruces, NM. Plants were transplanted in 1-m-wide rows, $30 \mathrm{~cm}$ apart, and rows were furrow irrigated. For both years, ripe yellow fruits (ready-to-eat) were harvested in August from healthy, established plants and transported to the laboratory for processing. Five fruits from each replicate were harvested in both years and three plants represented three replicates. Fruits were deseeded, cut, and weighed into pieces under yellow or dim light to prevent oxidation caused by blue light wavelengths. The pericarp tissue was flash frozen in liquid nitrogen, lyophilized, and ground to a fine powder using a coffee bean grinder.

Carotenoid analysis. Under yellow lights, $1 \mathrm{~g}$ of finely ground lyophilized tissue was extracted using a method modified from Guzman et al. (2010). Initially, $15 \mathrm{~mL}$ petroleum ether:acetone (1:1 v:v) (Sigma-Aldrich Corp., St. Louis, MO) was added followed by sonication for $20 \mathrm{~min}$ in a sonicating bath. The sample was centrifuged at $2900 \mathrm{rpm}$ for $10 \mathrm{~min}$ at $10{ }^{\circ} \mathrm{C}$. The same procedure was repeated two additional times with $15 \mathrm{~mL}$ hexane (Sigma-Aldrich Corp.) as the extraction solvent. All supernatants were combined in an amber glass vial and dried down under a stream of nitrogen gas. The residue was then saponified to de-esterify carotenoids using a previously published method (Richins et al., 2014). After saponification, dried extracts were resuspended in $500 \mu \mathrm{L}$ of spectrophotometrygrade isopropanol (Sigma-Aldrich Corp.). The samples were centrifuged to remove any debris and the supernatant was transferred to a highperformance liquid chromatography (HPLC) amber glass vial.

The samples were analyzed using a Waters HPLC system (Waters Corporation, Milford, MA) equipped with a Waters 600 controller and an In-Line Degasser AF, and a $4.6 \times 250-\mathrm{mm}, 5-\mu \mathrm{m}, \mathrm{YMC}$ C30 Carotenoid Column (YMC America, Allentown, PA). The solvent system, adapted from Richins et al. (2014), was a gradient method of two solvents, solvent A, methanol:tert-butyl methyl ether (MTBE):water (81:15:4), and solvent B, methanol:MTBE: water (8:88:4). The gradient included two linear phases $(0 \%$ to $67 \% \mathrm{~B}$ from 0 to $30 \mathrm{~min}$, then $67 \%$ to $90 \%$ B from 30-40 min). Flow rate was set at 3.0 $\mathrm{mL} / \mathrm{min}$, column temperature was $25^{\circ} \mathrm{C}$, and injection volume was $20 \mu \mathrm{L}$. A Waters 996 Photodiode Array Detector (PDA) collected spectral absorbance data from $230 \mathrm{~nm}$ to $700 \mathrm{~nm}$ and chromatographic peaks for each sample were detected at $450 \mathrm{~nm}$ using Waters Empower 2 software (Waters Corporation). Peaks were quantified using retention times and visible light spectra of lutein and $\beta$ carotene standards (Sigma-Aldrich Corp.). Serial dilutions of lutein and $\beta$-carotene were prepared with 50:50 hexane and isopropanol. Unknown peaks were identified as a carotenoid if its spectrum between $230 \mathrm{~nm}$ and $700 \mathrm{~nm}$ resembled that of a carotenoid per Britton et al. (2009). If the peak's spectrum resembled a carotenoid spectrum, the peak was labeled a carotenoid, and total carotenoids were quantified using the $\beta$-carotene standard curve (Guzman et al., 2010).

Phenolics analysis. Total phenolics were extracted from the lyophilized powder and the method was adapted from Singleton et al. (1999). Approximately $0.5 \mathrm{~g}$ of each sample was extracted with $8 \mathrm{~mL}$ of the $2 \%$ acetic acid in $80 \%$ aqueous methanol. The sample was sonicated for $10 \mathrm{~min}$ at $45^{\circ} \mathrm{C}$. After sonication, the sample was centrifuged at $2900 \mathrm{rpm}$ for $10 \mathrm{~min}$ at $4{ }^{\circ} \mathrm{C}$. The supernatant was transferred to a $25-\mathrm{mL}$ volumetric flask. The same pellet was re-extracted with $8 \mathrm{~mL}$ of solvent two more times, for a total of three pellet extractions per sample. The final extraction volume in the $25-\mathrm{mL}$ volumetric flask was made up to $25 \mathrm{~mL}$ using the extraction solvent. The extract was stored at $-20{ }^{\circ} \mathrm{C}$ until further use. The Folin-Ciocalteu assay was used in a 96-well plate (Singleton et al., 1999). Extracts were read against the phenolic gallic acid standard (SigmaAldrich) using a Molecular Devices SpectraMax M2 spectrophotometer (Molecular Devices, LLC, San Jose, CA) set at $765 \mathrm{~nm}$.

Statistical analysis. Means for each sample and analytical standard calibration curves were prepared using Microsoft Excel (Microsoft Corporation, Redmond, WA). Concentrations were plotted against peak areas to obtain a linear regression equation with an Rvalue higher than 0.95 per Richins et al. (2014). Concentrations for each sample were calculated based on the standard curves. 


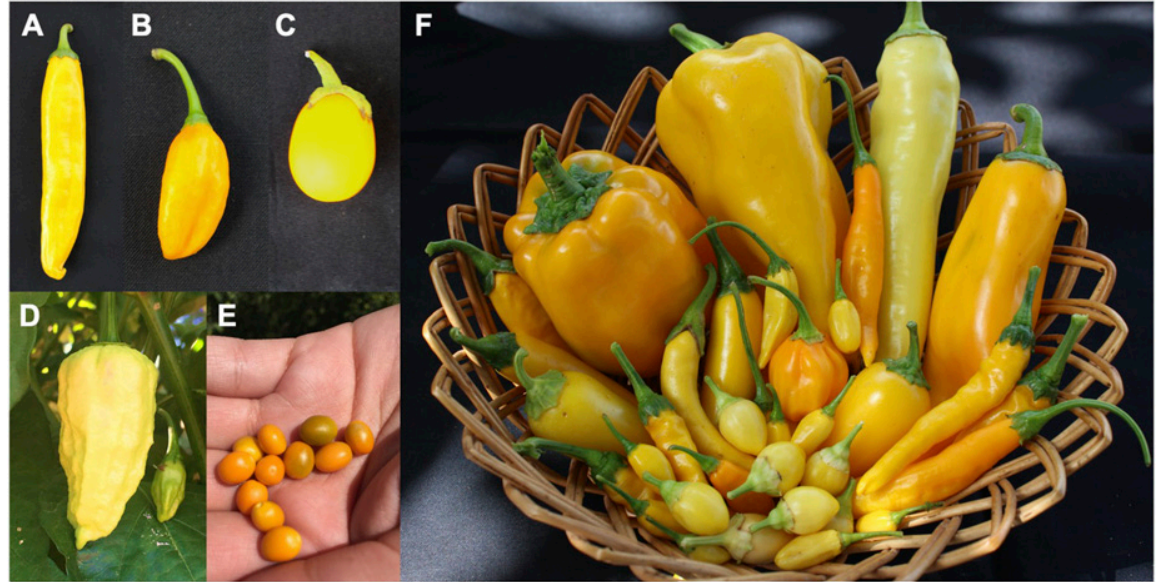

Fig. 1. Images of Capsicum spp. fruits and an eggplant, Solanum melongena, that ripen to a final yellow color: (A) 'NuMex Sunrise', a Capsicum annuum, (B) 'Aji Puchomucho', a Capsicum baccatum, (C) 'Thai Yellow Egg', S. melongena, (D) 'Fatali', Capsicum chinense, (E) 'Wild Chiltepin', C. annuum, and $(\mathbf{F})$ a basket of genetically distinct ripe yellow Capsicum fruits with diverse pod types.
Accession means and standard deviations were calculated using Microsoft Excel. Hierarchical clustering and principal component analysis (PCA) of the accessions based on all the metabolite means were generated using JMP Statistical (JMP 14.3.0, Medmenham, Marlow, Buckinghamshire, UK).

\section{Results and Discussion}

All 31 Capsicum accessions from three species (C. annuum, C. baccatum, and $C$. chinense) and the eggplant differed in phenotypic pod shape and all were yellow in their final ripening stage (Fig. 1). In spite of their shared color, their nutraceutical pigment content differed considerably when measured using HPLC, and this observation is in agreement with previous results published on Capsicum (Guzman et al., 2010). Figure 2 reveals the variation in HPLC carotenoid chromatograms of two Capsicum accessions. 'Thai
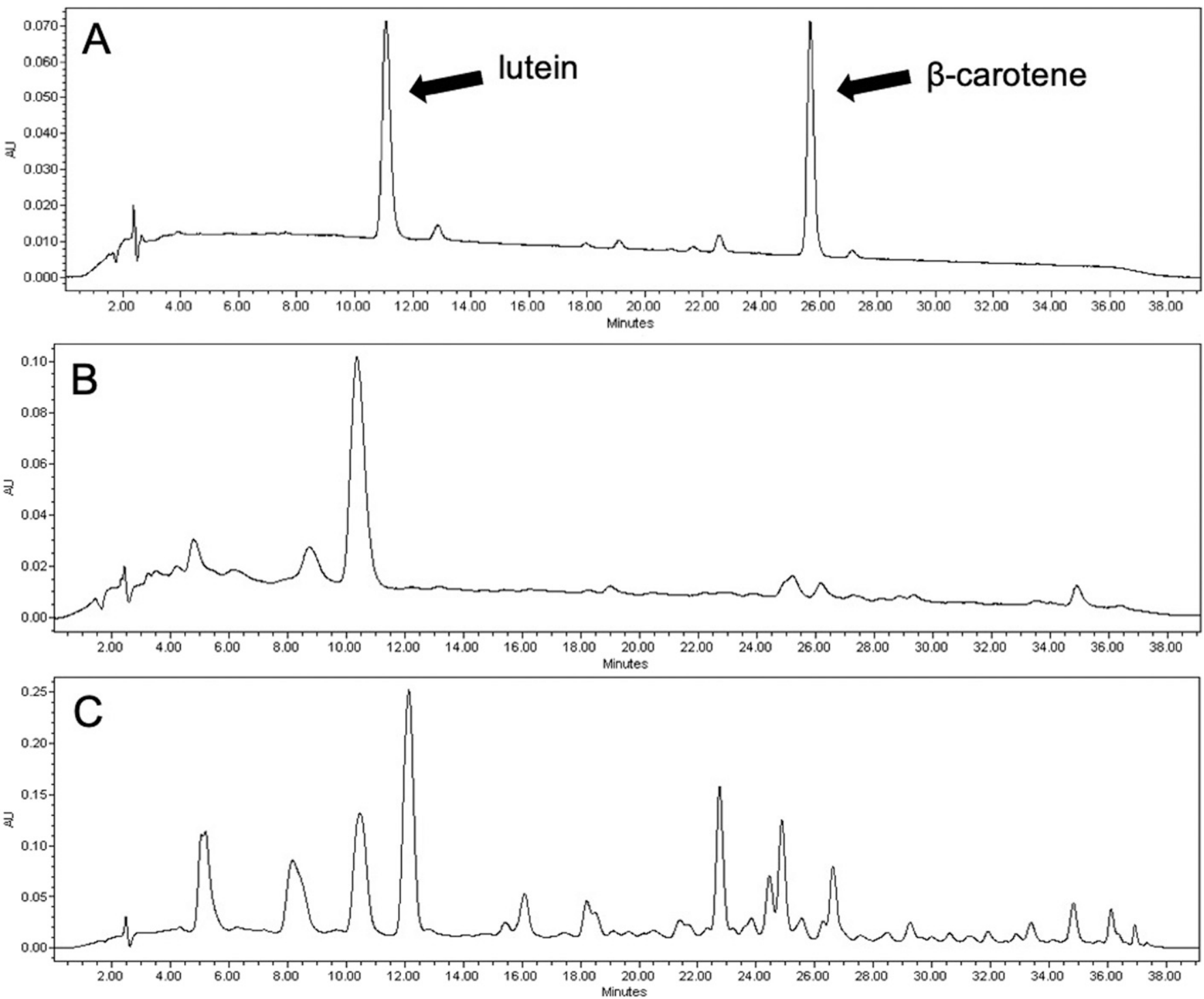

Fig. 2. High-performance liquid chromatography chromatograms of (A) two carotenoid standards, lutein and $\beta$-carotene with 11 and 25 min as retention times, respectively, (B) 'Wild Chinense', Capsicum chinense, with $66 \%$ of total carotenoids as lutein, and (C) 'Yellow Chiltepin', Capsicum annuum, with only $6.10 \%$ of total carotenoids as lutein. 


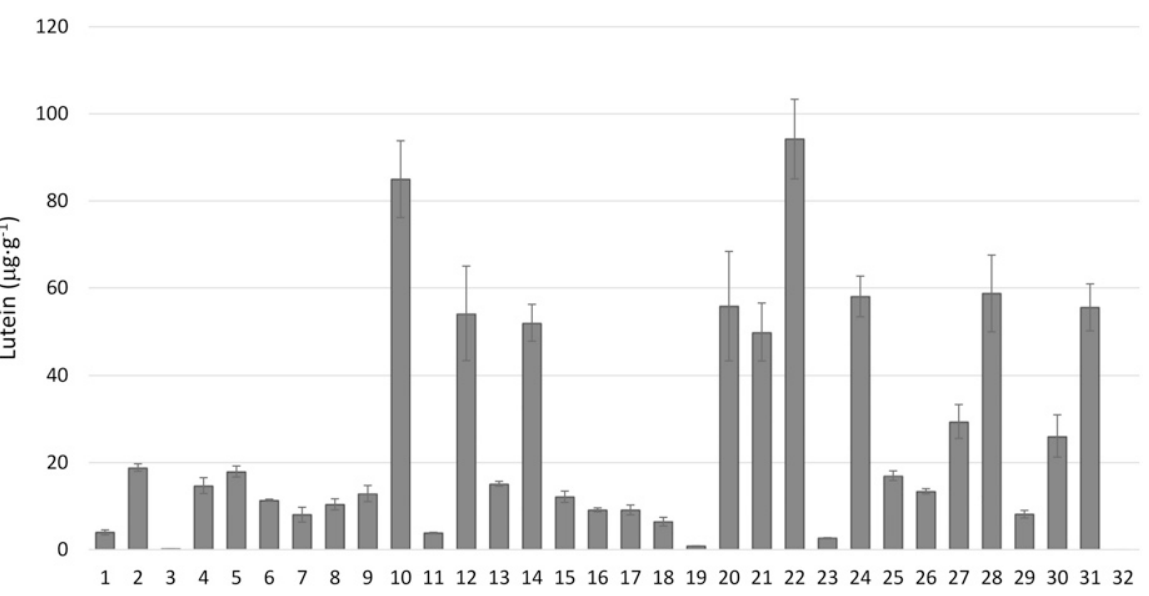

Fig. 3. Lutein content ( $\mu \mathrm{g} \cdot \mathrm{g}^{-1}$ dry weight) by high-performance liquid chromatography in each Capsicum accession. Data represent the mean from two independent experiments \pm SD from 2 years with at least three plants per year.

Yellow Egg' (accession 32) contained 19.38 $\mu \mathrm{g} \cdot \mathrm{g}^{-1}$ of total carotenoids on a DW basis (Table 1); however, the Capsicum accessions ranged from 4.70 to $767.20 \mu \mathrm{g} \cdot \mathrm{g}^{-1} \mathrm{DW}$ in total carotenoid concentration. 'Jamaican Hot Yellow', a C. chinense accession (accession 22), contained the lowest concentration chinense accession, 'Yellow Habanero' (accession 28), contained the highest concentration of total carotenoids across all accessions (Table 1). Lutein concentrations in Capsicum ranged from 0.14 to $94.2 \mu \mathrm{g} \cdot \mathrm{g}^{-1} \mathrm{DW}$ in 16C353 (accession 3) and 'Jamaican Hot of total carotenoids, whereas another $C$.
Yellow' (accession 22), respectively. The concentrations of $\beta$-carotene also varied from below detection for several Capsicum accessions (accessions 11, 19, 23, and 29) to 70.62 $\mu \mathrm{g} \cdot \mathrm{g}^{-1} \mathrm{DW}$ in 'Yellow Habanero' (accession 28), respectively.

Lutein, a yellow carotenoid, was variable among all ripe yellow accessions, therefore a mixture of other carotenoids and phenolics contributed to the overall color. Moreover, there was high variability between the concentrations of $\beta$-carotene relative to lutein per accession (Table 1). Only four Capsicum accessions and the eggplant contained higher concentrations of $\beta$-carotene than lutein of total carotenoids. These included 'Yellow Chiltepin', 'Burkina Yellow', 'Yellow Berk', and 'Yellow Habanero'. The other 27 accessions contained higher concentrations of lutein than $\beta$-carotene (Table 1 ).

Figure 3 illustrates concentrations of lutein per accession and the percentage of total carotenoids expressed as lutein. For nine accessions, namely $15 \mathrm{C} 388$ (accession 2), 16C469 (accession 7), 'Golden Cayenne' (accession 11), 'NuMex Lemon Spice' (accession 13), 'NuMex Sunrise' (accession 16), 'Yellow Hot' (accession 18), 'Peruvian Yellow' (accession 23), 'Wild Chinense' (accession 26),

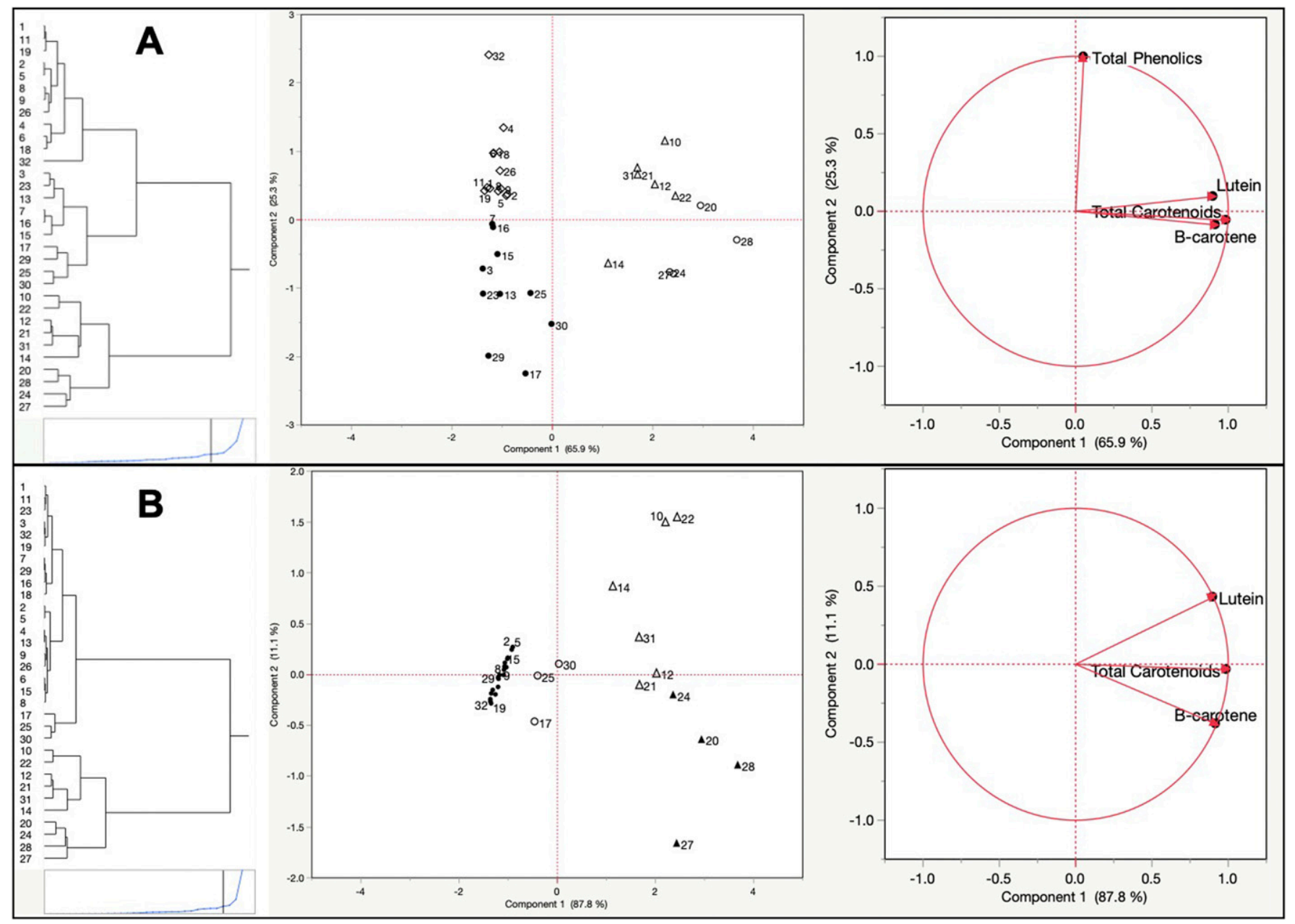

Fig. 4. Clustering, multivariate principal component analysis (PCA) plot, of sample observations for (A) total phenolics as gallic acid equivalents, total carotenoids, lutein, and $\beta$-carotene, and (B) total carotenoids, lutein, and $\beta$-carotene. 
and 'Aji Limon' (accession 29), lutein comprised $50 \%$ or more of their total carotenoid content. 'Wild Chinense' (accession 26) contained the highest percent of lutein, $66.30 \%$ of total carotenoids.

Total phenolics measured in the $31 \mathrm{Cap}$ sicum accessions ranged from 5.79 to 15.01 mg. $\mathrm{g}^{-1}$ (Table 1). 'Yellow Chiltepin' (accession 17) contained the lowest concentration of total phenolics, whereas 16C358 (accession 4) contained the highest concentration. By comparison, 'Thai Yellow Egg' (accession 32) contained the highest total phenolic concentration of all samples at $17.96 \mathrm{mg} \cdot \mathrm{g}^{-1}$, higher than that previously reported (Carvalho et al., 2015; de Aguiar et al., 2016; Joshi et al., 2017).

The hierarchical clustering and PCA plots indicated that there were four groups of accessions that shared similarities in total phenolics, total carotenoids, lutein, and $\beta$-carotene concentrations (Fig. 4A). Four groups also resulted based on similarities of total carotenoid concentrations, lutein and $\beta$-carotene concentration (Fig. 4B). Moreover, the accessions did not cluster based on species. In addition, as seen in the PCA results, yellow color is not a good indicator of lutein content given that the PCA summary plots indicated four unique groups and all quantified pigment variables had a positive influence on principal component one. Both PCA and cluster analysis showed that chemical profiles of the 31 accessions are independent of plant species.

The importance of understanding pigments in Capsicum fruits is useful when determining the nutraceutical value of an accession. Total carotenoids, lutein, $\beta$-carotene, and total phenolics are involved in overall color phenotype. Even though they are all beneficial to human health, their human health properties are different from one another. Lutein is not only a carotenoid with strong antioxidant properties but it can enter the bloodstream and is crucial as the human macular pigment that protects human eyes from age-related macular degeneration (Bernstein et al., 2016). The results of the 31 accessions proves that not all pigments with health benefits are accumulated in the same concentrations in Capsicum fruits that are all the same color.

\section{Conclusion}

In a previous study profiling Capsicum accessions, total carotenoid concentrations were as high as $3733.00 \mu \mathrm{g} \cdot \mathrm{g}^{-1} \mathrm{DW}$ and the lutein concentrations ranged from not detected to $70.18 \mu \mathrm{g} \cdot \mathrm{g}^{-1}$ DW (HervertHernandez et al., 2010). In this study, the accessions from the three species $(C$. annuum, $C$. baccatum, and $C$. chinense) that contained the highest total carotenoid concentration were the accessions with the highest lutein amount. However, the novelty of this study is that the percent lutein of total carotenoid concentrations varied from one accession to the other. Accessions of interest to breeders and growers could be those containing high percentages of lutein per total carotenoids. These accessions have genetics that drive the carotenoid pathway to producing mostly lutein instead of other carotenoids. In conclusion, the analysis of 31 Capsicum accessions indicates that Capsicum has the potential to be a valuable source of lutein for dietary uses.

\section{Literature Cited}

Arimboor, R., R.B. Natarajan, K.R. Menon, L.P Chandrasekhar, and V. Moorkoth. 2015. Red pepper (Capsicum annuum) carotenoids as a source of natural food colors: Analysis and stability-a review. J. Food Sci. Technol. 52:1258-1271, doi: 10.1007/s13197014-1260-7.

Bernstein, P.S., B. Li, P.P. Vachali, A. Gorusupudi, R. Shyam, B.S. Henriksen, and J.M. Nolan. 2016. Lutein, zeaxanthin, and meso-zeaxanthin: The basic and clinical science underlying carotenoid-based nutritional interventions against ocular disease. Prog. Retin. Eye Res. 50:34-66, doi: 10.1016/j.preteyeres.2015.10.003.

Britton, G., S. Liaaen-Jensen, and H. Pfander. 2009. Carotenoids volume 5: Nutrition and health. Birkhauser Verlag, Basel, Switzerland.

Bosland, P. and S. Walker. 2014. Growing chiles in New Mexico. New Mexico State Univ. Coop. Ext. Serv. H-230.

Brown, A.F., G.G. Yousef, I. Guzman, K.K. Chebrolu, D.J. Werner, M. Parker, K. Gasic, and P. Perkins-Veazie. 2014. Variation of carotenoids and polyphenolics in peach and implications on breeding for modified phytochemical profiles. J. Amer. Soc. Hort. Sci. 139:676-686, doi: 10.21273/JASHS.139.6.676.

Carrizo García, C., M.H.J. Barfuss, E.M. Sehr, G.E. Barboza, R. Samuel, E.A. Moscone, and F. Ehrendorfer. 2016. Phylogenetic relationships, diversification and expansion of chili peppers (Capsicum, Solanaceae). Ann. Bot. 118:35-51, doi: 10.1093/aob/mcw079.

Carvalho, A.V., R. de Andrade Mattietto, A. de Oliveira Rios, R. de Almeida Maciel, K.S Moresco, and T.C. de Souza Oliveira. 2015. Bioactive compounds and antioxidant activity of pepper (Capsicum sp.) genotypes. J. Food Sci. Technol. 52:7457-7464, doi: 10.1007/ s13197-015-1833-0.

Cichewicz, R.H. and P.A. Thorpe. 1996. The antimicrobial properties of chile peppers (Capsicum species) and their uses in Mayan medicine. J. Ethnopharmacol. 52:61-70, doi: 10.1016/ 0378-8741(96)01384-0.

de Aguiar, A.C., J.P. Coutinho, G.F. Barbero, H.T Godoy, and J. Martínez. 2016. Comparative study of capsaicinoid composition in Capsicum peppers grown in Brazil. Intl. J. Food Prop. 19:1292-1302, doi: 10.1080/10942912.2015. 1072210.

Guzman, I., P.W. Bosland, and M.A. O'Connell. 2011. Heat, color, and flavor compounds in Capsicum fruit, p. 109-126. In: D.R. Gang (ed.). The biological activity of phytochemicals. Springer, New York, NY. doi: 10.1007/ 978-1-4419-7299-6_8.

Guzman, I., M.H. Grace, G.G. Yousef, I. Raskin, and M.A. Lila. 2015. Novel strategies for capturing health-protective mango phytochemicals in shelf stable food matrices. Intl. J. Food Sci. Nutr. 66:175-185, doi: 10.3109/09637486. 2014.979315

Guzman, I., S. Hamby, J. Romero, P.W. Bosland, and M.A. O'Connell. 2010. Variability of carotenoid biosynthesis in orange colored Capsicum spp. Plant Sci. 179:49-59, doi: 10.1016/ j.plantsci.2010.04.014.
Hervert-Hernandez, D., S.G. Sayago-Ayerdi, and I. Goñi. 2010. Bioactive compounds of four hot pepper varieties (Capsicum annuиm L.), antioxidant capacity, and intestinal bioaccessibility. J. Agr. Food Chem. 58:3399-3406, doi: 10.1021/jf904220w

Joshi, D.D., S. Changkija, W. Sujata, B.G. Somkuwar, V.S. Rana, and N.C. Talukdar. 2017. Nutraceutical from Capsicum chinense fruits in shelf-stable herbal matrix. Innov. Food Sci. Emerg. Technol. 42:130-137, doi: 10.1016/ j.ifset.2017.06.006.

Kanarek, R.B. 2011. Artificial food dyes and attention deficit hyperactivity disorder. Nutr. Rev. 69:385-391, doi: 10.1111/j.1753-4887.2011. 00385.x.

Kim, J.S., C.G. An, J.S. Park, Y.P. Lim, and S. Kim. 2016a. Carotenoid profiling from 27 types of paprika (Capsicum annuum L.) with different colors, shapes, and cultivation methods. Food Chem. 201:64-71, doi: 10.1016/j.foodchem. 2016.01.041.

Kim, Y., J.B. Keogh, and P.M. Clifton. 2016b. Polyphenols and glycemic control. Nutrients 8:17, doi: 10.3390/nu8010017.

Ksibi, I.E., R.B. Slama, K. Faidi, M.B. Ticha, and M.F. M'henni. 2015. Mixture approach for optimizing the recovery of colored phenolics from red pepper (Capsicum annum L.) byproducts as potential source of natural dye and assessment of its antimicrobial activity. Ind. Crops Prod. 70:34-40, doi: 10.1016/ j.indcrop.2015.03.017.

Lipkie, T.E., A.L. Morrow, Z.E. Jouni, R.J. McMahon, and M.G. Ferruzzi. 2015. Longitudinal survey of carotenoids in human milk from urban cohorts in China, Mexico, and the USA. PLoS One 10:e127729, doi: 10.1371/ journal.pone.0127729.

Materska, M. and I. Perucka. 2005. Antioxidant activity of the main phenolic compounds isolated from hot pepper fruit (Capsicum annuиm L.). J. Agr. Food Chem. 53:1750-1756.

McCann, D., A. Barrett, A. Cooper, D. Crumpler, L. Dalen, K. Grimshaw, E. Kitchin, K. Lok, L. Porteous, E. Prince, E. Sonuga-Barke, J.O. Warner, and J. Stevenson. 2007. Food additives and hyperactive behaviour in 3-year-old and $8 /$ 9-year-old children in the community: A randomised, double-blinded, placebo-controlled trial. Lancet 370:1560-1567, doi: 10.1016/ S0140-6736(07)61306-3.

Minatel, I.O., C.V. Borges, M.I. Ferreira, H.A.G. Gomez, C.Y.O. Chen, and G.P.P. Lima. 2017. Phenolic compounds: Functional properties, impact of processing and bioavailability, p. 1-24. In: M. Soto-Hernandez, M. PalmaTenango, and M.D.R. Garcia-Mateos (eds.). Pehnolic compounds - biological activity. Intech, Rijeka, Croatia. doi: 10.5772/66368.

Richins, R.D., J. Kilcrease, L. Rodgriguez-Uribe, and M.A. O'Connell. 2014. Carotenoid extraction and quantification from Capsicum annuum. Bio Protoc. 4(19):e1256, doi: 10.21769/ BioProtoc. 1256

Rodriguez-Amaya, D.B. 2019. Update on natural food pigments - A mini-review on carotenoids, anthocyanins, and betalains. Food Res. Int. 124:200-205, doi: 10.1016/j.foodres.2018. 05.028 .

Singleton, V.L., R. Orthofer, and R.M. LamuelaRaventós. 1999. Analysis of total phenols and other oxidation substrates and antioxidants by means of folin-ciocalteu reagent. Methods Enzymol. 299:152-178, doi: 10.1016/S00766879(99)99017-1.

Stommel, J.R. and R.J. Griesbach. 2008. Inheritance of fruit, foliar, and plant habit attributes in 
Capsicum. J. Amer. Soc. Hort. Sci. 133:396407, doi: 10.21273/JASHS.133.3.396.

Taofiq, O., A.M. Gonzalez-Paramas, M.F. Barreiro, I.C.F.R. Ferreira, D.J. Mc, and D.J. Phee. 2017. Hydroxycinnamic acids and their derivatives: Cosmeceutical significance, challenges and future perspectives, a review. Molecules 22(2):281, doi: 10.3390/molecules22020281.

Waterhouse, A.L. 2002. Determination of total phenolics, p. I1.1.1-I1.1.8. In: R.E. Wrolstad (ed.).
Current protocols in food analytical chemistry. John Wiley \& Sons, Inc., New York, NY.

Yousef, G.G., A.F. Brown, I. Guzman, J.R. Ballington, and M.A. Lila. 2016. Variations in chlorogenic acid levels in an expanded gene pool of blueberries. AIMS Agr. Food 1:357368, doi: 10.3934/agrfood.2016.3.357.

Yousef, G.G., M.H. Grace, J.L.G. Medina, S. Neff, I. Guzman, A.F. Brown, I. Raskin, and M.A. Lila. 2014a. Concentrating immunoprotective phytoactive compounds from fruits and vegetables into shelf-stable protein-rich ingredients Plant Foods Hum. Nutr. 69:317-324, doi 10.1007/s11130-014-0445-6.

Yousef, G.G., M.A. Lila, I. Guzman, J.R. Ballington, and A.F. Brown. 2014b. Impact of interspecific introgression on anthocyanin profiles of Southern highbush blueberry. J. Amer. Soc. Hort. Sci. 139:99-112, doi: 10.21273/JASHS. 139.2.99. 